\title{
Regional climate change of the greater Zambezi River Basin: a hybrid assessment
}

\author{
C. Adam Schlosser • Kenneth Strzepek
}

Received: 21 June 2013 / Accepted: 12 August 2014 / Published online: 26 September 2014

(C) UNU-WIDER 2014. This article is published with open access at Springerlink.com

\begin{abstract}
Projections of regional changes in surface-air temperature and precipitation, in response to unconstrained emissions as well as a climate mitigation policy, for the Zambezi River Basin (ZRB) are presented. These projections are cast in a probabilistic context through a hybrid technique that combines the projections of the MIT Integrated Global System Model (IGSM) to pattern-change kernels from climate-model results of the Coupled Model Intercomparison Project (CMIP). Distributional changes of precipitation and surface-air temperature averaged over the western and eastern ZRB are considered. Overall, the most significant response to climate policy is seen in the spring. Frequency distributions of precipitation change for the unconstrained emission scenario indicate a majority of the outcomes to be drier by 2050 , although the distribution spans both increased and decreased precipitation. Through climate policy, the distributions' total range of outcomes collapses considerably, and perhaps more importantly, the mode of the distribution aligns with zero precipitation change. For surface-air temperature, climate policy consistently reduces the modal value of warming, and this reduction is strongest for the western ZRB. Climate policy also considerably abates the occurrence of the most extreme temperature increases, but the minimum warming in the distributions is less affected.
\end{abstract}

\section{Introduction}

Growing demands for climate-change vulnerability assessments and adaptation strategies have placed a need for risk-based quantification of regional change. Considerable attention has been directed toward developing nations where the capability to make informed decisions and/or capital investments based on risks from climate and socioeconomic changes are at a premium. In this study, we present analyses for the greater

This article is part of a Special Issue on "Climate Change and the Zambezi River Valley" edited by Finn Tarp, James Juana, and Philip Ward.

C. A. Schlosser $(\bowtie) \cdot K$. Strzepek

Joint Program on the Science and Policy of Global Change, Massachusetts Institute of Technology, 77

Massachusetts Ave, E19-411, 02139-4307 Cambridge, MA, USA

e-mail: casch@mit.edu 
Zambezi River Basin (ZRB) that quantifies the likelihood of changes in precipitation and surface-air temperature through the middle of this century. These probabilistic climate projections have been prepared as inputs into a linked model framework with the goal to assess the impacts of future changes in climate and global policy on the economic activity of Mozambique. The overall framework and results of this linked model framework to assess Mozambique are presented in the remaining papers of this special issue. In the sections that follow herein, we present a summary of the methodology and climate-change distributions constructed for these multi-disciplinary model experiments and assessments. The construction of these distributions is based on a "hybrid" approach, which combines large ensemble simulations using an intermediate complexity earth-system model and pattern-change kernels derived from climate-model results of the Coupled Model Intercomparison Project Phase 3 (CMIP3, Meehl et al. 2007). We present the distributions of seasonally-averaged precipitation and surface-air temperature change that result from an unconstrained emissions pathway as well as a climate-stabilization policy. In Section 2.3, these distributions are provided for the climate variables averaged over two large subregions - western Zambezi (WZMB) region and eastern Zambezi (EZMB) region (denoted in Fig. 1), in order to provide consistent context with the results of other companion papers in this special issue. Closing remarks and directions for future work are then provided in Section 3.
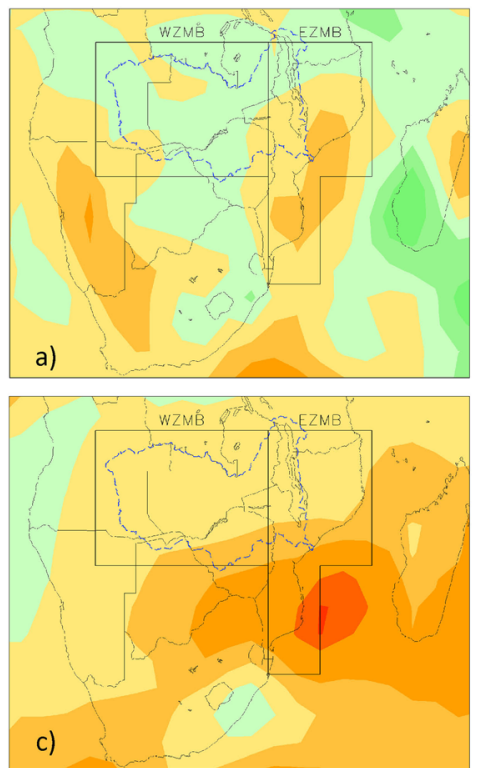
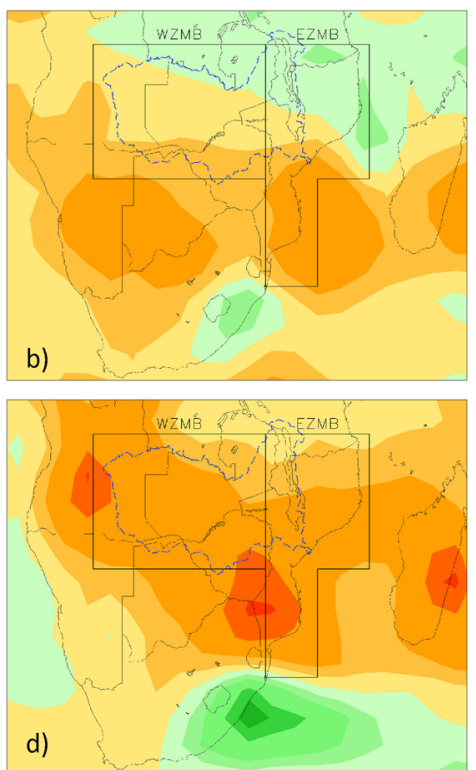

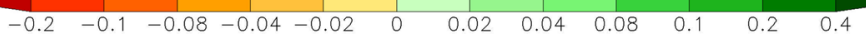

Fig. 1 Maps of the transformation coefficients, $d C x, y / d T G l o b a l$ (units of K-1) over southern Africa for precipitation averaged over the results from the CMIP3 climate models. Shown are the seasonally averaged pattern shifts averaged for: a) December-February, b) March-May, c) June-August, and d) September-November. In each frame, the western Zambezi (WZMB) and eastern Zambezi (EZMB) averaging domains are outlined, which are used in constructing the hybrid frequency distributions (HFDs). In addition, the blue dashed area denotes the Zambezi River Basin (ZRB) considered in this study as well as the other companion papers of the special issue impact study 


\section{Characterizations of regional climate shifts}

\subsection{Greater Zambezi River Basin (ZRB)}

The ZRB (denoted in Fig. 1) is our area of focus for this risk-based assessment of regional change. As noted above, the linked set of impact models that assess the risks to the Mozambique economy (refer to corresponding papers in this special issue), require two climate variables as inputs: precipitation and near-surface air temperature $\left(T_{a}\right)$. These impact models are configured to resolve large sub-basins and demographic regions of the basin, and the climate variables are provided at a $2 \times 2^{\circ}$ grid resolution. Given this, the EZMB region contains $222 \times 2^{\circ}$ grid cells and the WZMB region contains $372 \times 2^{\circ}$ grid cells. Overall, this region of southern Africa is characterized by a strong seasonality in precipitation and $T_{a}$. A detailed description is provided in Schlosser and Strzepek (2013, refer to the discussion surrounding their Figs. 2 and 3). To summarize here, over most of the basin, a modest seasonal swing in temperature is experienced and is on the order of $4{ }^{\circ} \mathrm{C}$, with the strongest seasonality within the interior portions of the basin. In contrast to $T_{a}$, the ZRB experiences a more notable precipitation seasonality (e.g. Novella et al. 2013 and Thiemig et al. 2012). A widespread dry season occurs during June-August. In contrast, much of the ZRB experiences averaged precipitation rates in excess of $5 \mathrm{~mm} /$ day, with a notable portion in excess of $8 \mathrm{~mm} /$ day, during December-February. Remnants of the dry season are seen during SeptemberNovember, but the northwestern most portion of the basin shows increased precipitation. Nevertheless, the September-November season is quite important agriculturally speaking given that it corresponds to the time of planting as well as the onset of the rainy season for most of this region (e.g. Hachigonta et al. 2008). A detailed analysis is beyond the scope of this paper, but given these distinct seasonal features of the basin, the subsequent analyses will,
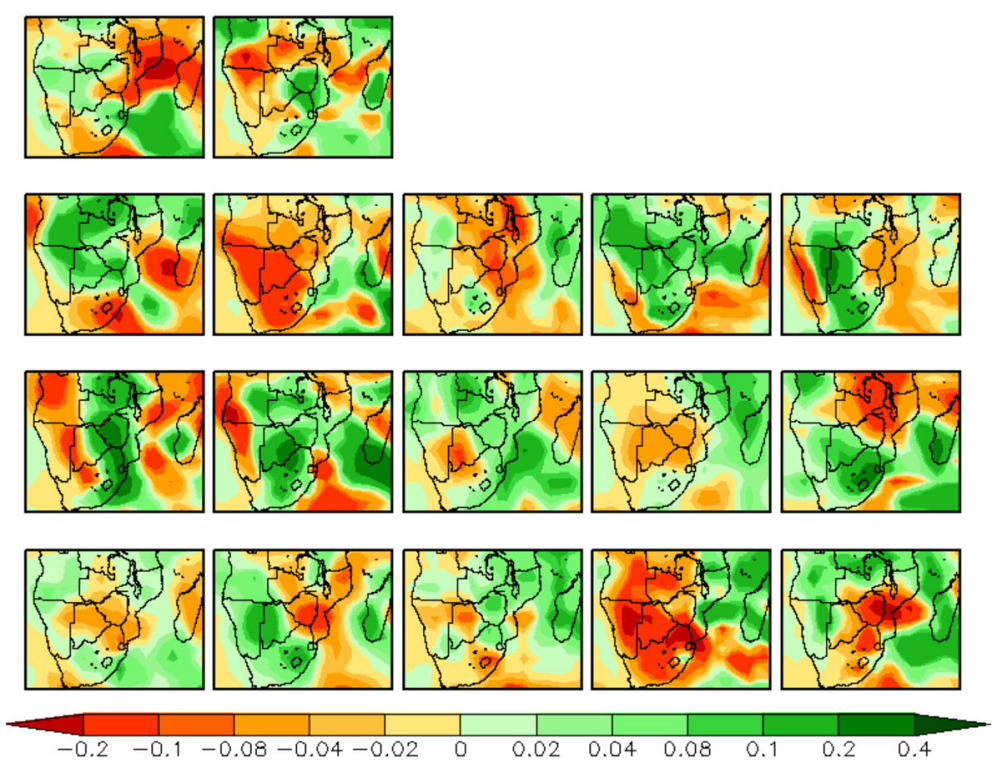

Fig. 2 Maps of the transformation coefficients, $d C x, y / d T G l o b a l$ (units of K-1) over southern Africa for precipitation. Shown are the results from 17 of the CMIP3 models of the seasonally pattern shifts averaged for December-February 

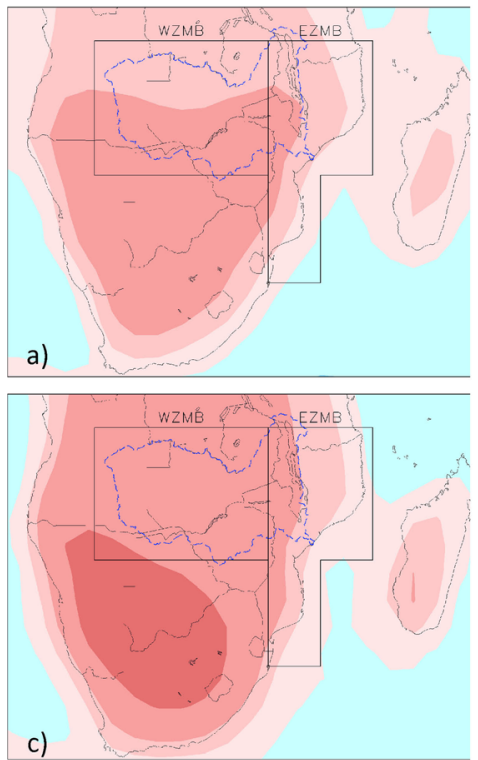
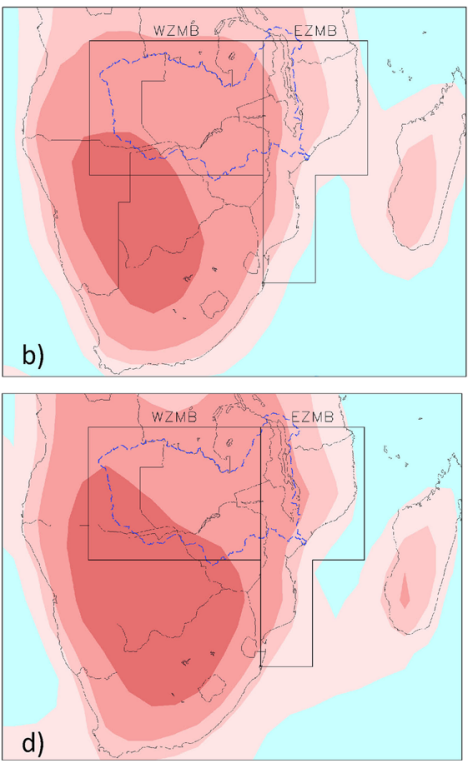

$\begin{array}{lllllll}-0.004-0.002-0.001-0.0005 & 0 & 0.0005 & 0.001 & 0.002 & 0.004 & 0.008\end{array}$

Fig. 3 Maps of the transformation coefficients, $d C x, y / d T G l o b a l$ (units of K-1) over southern Africa for surfaceair temperature based averaged over the results from the CMIP3 climate models. Shown are the seasonally averaged pattern shifts averaged for: a) December-February, b) March-May, c) June-August, and d) SeptemberNovember. In each frame, the western Zambezi (WZMB) and eastern Zambezi (EZMB) averaging domains are outlined, which are used in constructing the hybrid frequency distributions (HFDs). In addition, the blue dashed area denotes the Zambezi River Basin (ZRB) considered in this study as well as the other companion papers of the special issue impact study

accordingly, present diagnoses of the potential seasonally averaged changes in these climate variables at 2050 .

\subsection{Pattern-change kernels of regional climate}

The construction of our presented frequency distributions of climate changes follows that of previously published work. The MIT Integrated Global Systems Model provides probabilistic projections of $T_{a}$ and precipitation out to the middle of this century (IGSM, Sokolov et al. 2009 and Webster et al. 2011). The IGSM contains an earth-system model of intermediate complexity. As such, the atmospheric outputs in the IGSM are explicitly resolved across latitudes, but not in the longitude. We then extrapolate these variables in the longitude through a Taylor expansion technique, described by Schlosser et al. (2012). This transformation requires the construction of pattern-change kernels as global temperature changes, and the overall numerical relationship is expressed as:

$$
V_{x, y}^{I G S M}\left(\Delta T_{\text {Global }}\right)=C_{x, y}||_{o} \bar{V}_{y}^{I G S M}+\left[\frac{d C_{x, y}}{d T_{\text {Global }}} \Delta T_{\text {Global }}^{I G S M}\right] \bar{V}_{y}^{I G S M}
$$

where $\left.C_{x, y}\right|_{t o}$ is the downscaling transformation coefficient between any zonal mean quantity, $\bar{V}_{y}^{I G S M}$, at latitude, $y$, to its value, $\bar{V}_{x, y}^{I G S M}$, at any corresponding longitudinal point, $x$, for any reference time period (in this case, 1981-2000, as in Schlosser et al. 2012). 
Accordingly, $\Delta T_{\text {Global }}$ is the (projected) change in global temperature that has occurred relative to the reference or climatological period. Then, based on supporting data the derivative of these transformation coefficients, $\frac{d C_{x, y}}{d T_{G i b a l}}$, for any point $(x, y)$ must be estimated, and the term serves as "pattern-change kernels" of regional climate shifts. As shown in (1), the patternchange kernels are scaled according to the global temperature change $\left(\Delta T_{\text {Global }}\right)$, and thus the regional specificity of the climate-change probabilities is governed, in large part, by the $\frac{d C_{x, y}}{d T_{\text {Global }}}$. Pattern-change kernels are calculated separately for 17 of the CMIP3 climate models that performed the experimental scenarios of greenhouse gas concentrations, and are calculated on a monthly basis to resolve an annual cycle. Further details as to the construction and calculation of all the terms in (1) can be found in Schlosser et al. (2012). In the sections that follow, we summarize the precipitation and $T_{a}$ results of the pattern-change kernels over the ZRB study region.

\subsubsection{Precipitation}

The mean of $\frac{d C_{x, y}}{d T_{\text {Global }}}$ for precipitation across all the CMIP3 models (Fig. 1) indicates that the most notable (relative) shifts in regional precipitation will occur during the spring (SeptemberNovember), as seen by the widespread negative $\frac{d C_{x_{x, y}}}{d T_{\text {Global }}}$ values - indicating a relative drying (with respect to the zonal mean) over the region as global climate warms. During the summer months (December-February), this situation is replaced with small positive values over western regions, but the negative values persist over much of the eastern regions. Only during the fall (March-May) does the eastern basin see a notable portion with positive values of $\frac{d C_{x, y}}{d T_{G l o b a l}}$ (indicating a relative increase in precipitation, with respect to the zonal mean, with climate warming). It should be noted that the zonal trends in precipitation are simulated by the IGSM in response to increased greenhouse gas concentrations. The region experiences a wide range of zonal precipitation trends (see Fig. 9 of Schlosser et al. 2012). Over the northern flank of the basin, the majority of the zonal precipitation trends are positive, while in the southern flank the sign of the zonal precipitation trends are equally distributed. This will, undoubtedly, factor considerably into the resulting frequency distributions of precipitation change for the basin (presented in later sections). Likewise, the range of precipitation-change patterns from each of the CMIP3 climate models also display very different features. During the spring (see Fig. 5 of Schlosser and Strzepek 2013), a few of the models exhibit enhanced drying over most of the basin, while the remaining models show weaker drying. During the summer (Fig. 2), the diversity among the models is quite pronounced; with a few models producing widespread enhanced precipitation patterns, while other models will impose enhanced widespread drying. The remaining models show a mixed pattern of drier or wetter precipitation conditions (relative to the zonal trend) as climate warms.

\subsubsection{Temperature}

In contrast to precipitation, the results of $\frac{d C_{x, y}}{d T_{\text {Global }}}$ for $T_{a}$ (Fig. 3) indicate a pattern that resembles the colder ocean and warmer land (COWL) global pattern (e.g. Broccoli et al. 1998), and this characterization is seen in the global maps of $\frac{d C_{x, y}}{d T_{\text {Global }}}$ from Schlosser et al. (2012). In terms of the model-mean response, this pattern is persistent for all seasons, with a small degree of migration of the relative maxima of change. In terms of the zonal mean trends, the IGSM produces a fairly consistent zonal profile of warming over the region (see Fig. 8 of Schlosser 
et al. 2012). Therefore, these patterns will essentially enhance the zonal warming (as the global climate warms) over the entire ZRB. However, there are regional enhancements to the COWL warming as a result of the choice of the pattern kernel, as evidenced by the scatter of these patterns amongst the CMIP3 models (see Figs. 8 and 9 of Schlosser and Strzepek 2013). Most of the models' pattern kernels place the area of strongest regionally enhanced warming to the south or just along the southern flank of the ZRB. Yet as indicated in the model mean pattern (Fig. 3), during the spring the majority of the models extend the strongest warming into a sizeable portion of the western basin, but during the summer, this enhancement is less prevalent.

\subsection{Hybrid frequency distributions}

Through the combination of the IGSM ensemble of zonal trends with each of the pattern kernels of regional climate change from the CMIP3 models, an ensemble of climate change projections is produced, and hereafter we refer to as "hybrid frequency distributions" (HFDs). For this presentation, we focus on the decadal-averaged climate conditions that are achieved at 2050 and construct frequency distributions of the changes in precipitation and $T_{a}$ relative to the end of the 20th century. Decadal averaged results are provided in order to highlight the salient features of low-frequency changes seen by mid-century and minimize effects of higher-frequency noise. In addition, given the distinct seasonal characterizations of the regional climate-change pattern kernels, and the importance of the spring and summer climate conditions as inputs to the agricultural impact models used in this larger integrated study this special issue, we focus in the distributions obtained during the September-November (SON) and December-February (DJF) averaging periods. The IGSM ensembles produce a range of climate outcomes under an unconstrained emissions pathway (Sokolov et al. 2009) as well as a range of global climate policies (Webster et al. 2011). In the interest of clarity, we focus on a subset of these climate projections. We present results for the unconstrained emissions (UCE) case and a modest greenhouse gas stabilization scenario in which an equivalent $\mathrm{CO}_{2}$ concentration of $\sim 650 \mathrm{ppm}$ is achieved by the end of the century - and is referred to as the "Level 2 stabilization" (L2S) policy in Webster et al. (2011).

\subsubsection{Western Zambezi (WZMB) region}

Looking at the UCE case, the resulting HFDs of the area-averaged $T_{a}$ changes for SON (Fig. 4) indicate that the mode of the temperature-change distribution to be in the $2.0-2.25^{\circ} \mathrm{C}$ range by 2050. The distribution shows a fairly robust Gaussian shape, but with skewness toward higher temperature increases. This skewness is consistent with some of the CMIP3 models' pattern kernels imposing a stronger warming over the sub-basin (Fig. 3d). The impact of the L2S climate policy is a modest reduction in the mode of warming by about $0.75{ }^{\circ} \mathrm{C}$, but more notably, the entire L2S distribution of warming lies at or below the bottom half of the UCE distribution. As a result, the highest warming of the L2S distribution coincides with the mode warming of the UCE distribution. Further, over 70 $\backslash$ of the L2S distribution lies at or below a $1.5{ }^{\circ} \mathrm{C}$ warming, whereas only $7 \%$ of UCE distribution occurs at or below this warming. Perhaps the more striking impact of the stabilization scenario is seen in the SON precipitation results (Fig. 5). Under the UCE pathway, the WZMB region exhibits a fairly broad range of outcomes, that span both decreases and increases in precipitation. However, the mode of precipitation change (with just over $20 \%$ of the distribution) lies rather saliently within decreased precipitation and is in the range of -0.2 to $-0.1 \mathrm{~mm} /$ day (note that in HFD figures of precipitation, values are presented in units of $\mathrm{mm} / \mathrm{decad}$, with decad $=10$ days). What is equally striking in the UCE distribution is the rather broad tail in the distribution, that result in precipitation increases as high as 0.7 to $0.8 \mathrm{~mm} /$ day and decreases as low as $-0.6 \mathrm{~mm} /$ day. The 


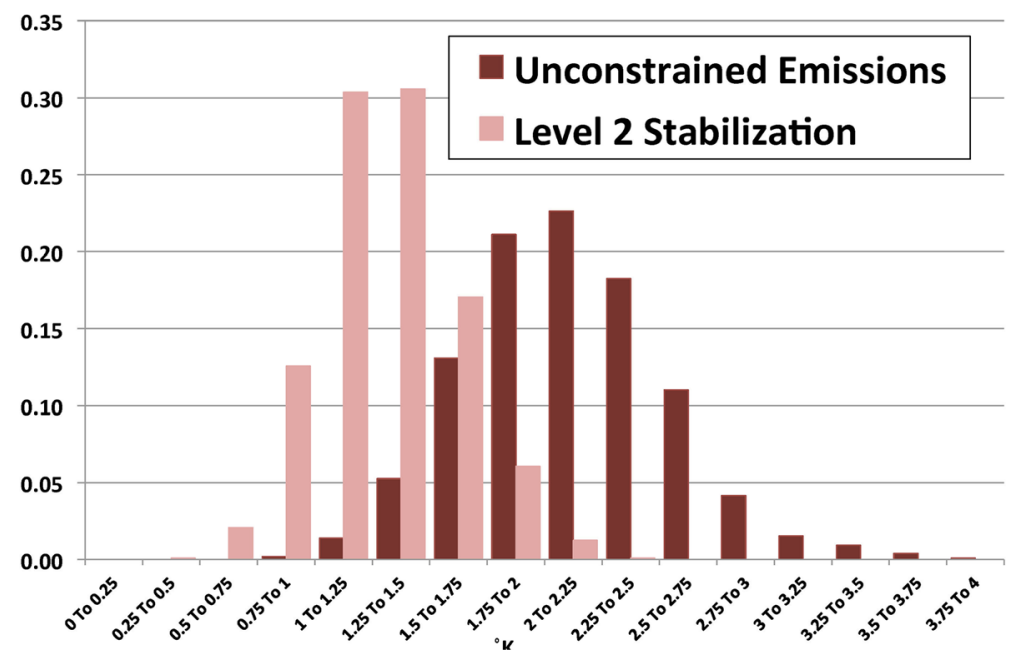

Fig. 4 Hybrid frequency distributions (HFDs) of decadal averaged September-November (SON) mean surfaceair temperature $(\mathrm{Ta})$ change (with respect to the last decade of the 20th century). The changes are area averaged for the Western Zambezi (WZMB) region. Shown are the decadal-averaged changes at 2050, based on the nopolicy IGSM ensemble simulation (dark red bars) and the Level 2 stabilization scenario (light red bars)

effect of the L2S climate-policy scenario on the HFD is considerable. The new mode value is half the value seen in the UCE case, and now contains $55 \%$ of the distribution. However, The L2S result still has nearly as much of the distribution $(\sim 20 \%)$ for the mode value of the UCE, but the long tailed features of the UCE distribution are not seen for the L2S case. Overall, less than $1 \%$ of the L2S distribution exceeds a $-0.2 \mathrm{~mm} /$ day reduction or $0.2 \mathrm{~mm} /$ day increase in precipitation (as opposed to $\sim 40$ and $8 \%$, respectively, for the UCE scenario).

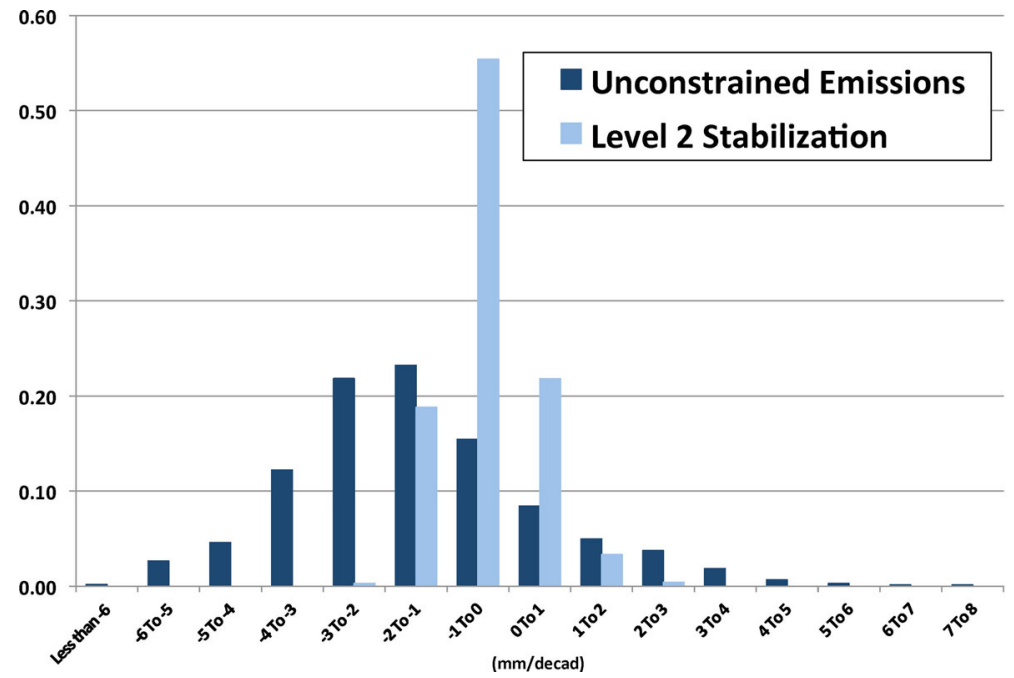

Fig. 5 Hybrid frequency distributions (HFDs) of decadal averaged September-November (SON) mean precipitation change (with respect to the last decade of the 20th century). The changes are area averaged for the Western Zambezi (WZMB) region. Shown are the decadal-averaged changes at 2050, based on the no-policy IGSM ensemble simulation (dark blue bars) and the Level 2 stabilization scenario (light blue bars) 
For the summer months (DJF), the shape and response of the HFDs for the two scenarios are a striking resemblance to that of the spring for $T_{a}$ (see Fig. 12 of Schlosser and Strzepek 2013). For the UCE scenario, the mode value of the DJF $T_{a}$ changes is the same as that of spring (SON); with a mode value of temperature increase is 2.0 to $2.25{ }^{\circ} \mathrm{C}$. For the $\mathrm{L} 2 \mathrm{~S}$ scenario, the mode of warming is reduced by $0.5^{\circ} \mathrm{C}$, and much of the $\mathrm{L} 2 \mathrm{~S}$ population resides in the lower half of the population of temperature warming seen in the UCE scenario. However, there is a small portion of the L2S population $(\sim 10 \%)$ that remains in the upper half of the warming outcomes of the UCE. In either scenarios, nearly all of the ensemblemember population results in a $1.0^{\circ} \mathrm{C}$ warming by 2050 . For precipitation change (see Fig. 13 of Schlosser and Strzepek 2013), the most densely populated portion of the distribution flanks the result of no change. However, there is a slight skewness in that $57 \%$ of the distribution results in increased precipitation, with $43 \%$ indicating a decrease. Further, the largest precipitation increases are greater in magnitude than the corresponding decreases. The impact of the L2S scenario primarily reduces the occurrence of the most extreme precipitation changes (both positive and negative), and the most extreme outcome is about $50 \%$ to that of the UCE. As a result, the increase in the portion of the population flanking no precipitation change is considerable, with nearly $45 \%$ of the population as opposed to $28 \%$ in the UCE.

\subsubsection{Eastern Zambezi (EZMB) region}

The HFDs for $T_{a}$ changes in the summer months for the EZMB region show the weakest response to climate policy among all the cases considered herein. The mode value of temperature increase is 1.25 to $1.5^{\circ} \mathrm{C}$ (see Fig. 14 of Schlosser and Strzepek 2013) and is comprised of $30 \%$ of the ensemble-member population. The effect of the L2S policy scenario is subtle with a slight decrease in the mode value $\left(0.25^{\circ} \mathrm{C}\right)$, and the mode now contains $37 \%$ of the ensemblemember population. For DJF precipitation changes, similar to the features noted for the WZMB region, the more densely populated regions of the HFDs in both scenarios considered lie quite close to the result of zero precipitation change by 2050 (see Fig. 15 of Schlosser and Strzepek 2013). Nevertheless, the skewness of the distribution tails and their shifts in response to the L $2 \mathrm{~S}$ scenario are notable. For the UCE case, $60 \%$ of the distribution results in increased precipitation, and the highest increases in precipitation exceed in magnitude any of the lowest decreases. The L2S scenario places an equal percentage of the population in both decreases and increases in precipitation (Fig. 15). In addition, a more salient modal feature of the distribution is found, which surrounds a result of the no precipitation change.

During the spring, the HFDs for $T_{a}$ changes exhibit a consistent behavior as seen for the WZMB region, but the mode of the temperature increase is slightly lower and found to be in the 1.0 to $1.25{ }^{\circ} \mathrm{C}$ range (Fig. 6). In addition, we find that the most extreme temperature increases for the EZMB region for SON (as well as DJF - shown in Schlosser and Strzepek 2013) are at least $1.0^{\circ} \mathrm{C}$ lower than those seen for the WZMB region. Nevertheless, the impact of the L2S policy is discernable. Although the decrease in the mode value of temperature warming is small (only a $0.25^{\circ} \mathrm{C}$ ), the increase in the portion of the population that resides in the mode is considerable (Fig. 6). The L2S contains nearly $43 \%$ of the distribution in the mode value of warming $\left(0.75\right.$ to $\left.1.0^{\circ} \mathrm{C}\right)$ as opposed to $25 \%$ for the UCE scenario. Similar to that found for the WZMB region, the features and shifts for SON precipitation change in both the UCE and L2S are among the most striking. For the UCE case, the mode of the distribution indicates a decrease in precipitation, with $40 \%$ of the ensemble-member population flanking a value of $-0.15 \mathrm{~mm} /$ day (Fig. 7). As a result, the majority of the population (91\%) projects decreased precipitation. However, the HFD exhibits very broad tails that span both decreases and increases in precipitation, yet only $9 \%$ of the population results in increased precipitation. 


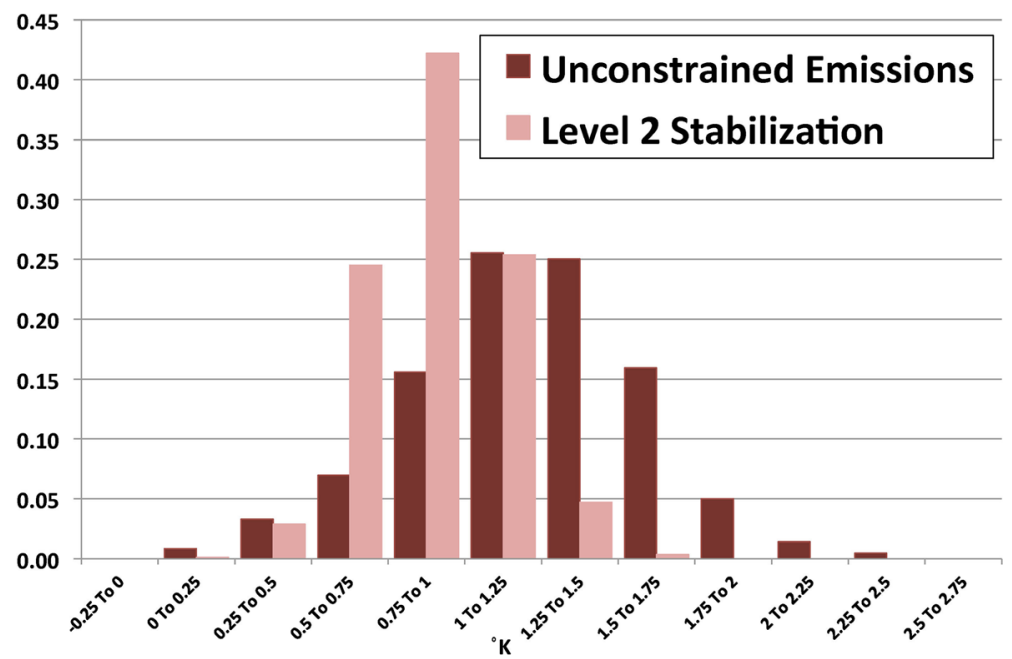

Fig. 6 Hybrid frequency distributions (HFDs) of decadal averaged September-November (SON) mean surfaceair temperature $(\mathrm{Ta})$ change (with respect to the last decade of the 20th century). The changes are area averaged for the Eastern Zambezi (EZMB) region. Shown are the decadal-averaged changes at 2050, based on the nopolicy IGSM ensemble simulation (dark red bars) and the Level 2 stabilization scenario (light red bars)

The effect of the L2S scenario is similar to that found in the WZMB region and is considerable. The total range of precipitation changes encompassed by the HFD is compressed by over a factor 3 (from $10 \mathrm{~mm} / \mathrm{decad}$ to $3 \mathrm{~mm} / \mathrm{decad}$ ). Most notably, however, is that over $75 \%$ of the distribution lie in the two bins that flank $-0.05 \mathrm{~mm} /$ day precipitation change. One of these is the mode value, -0.1 to $0.05 \mathrm{~mm} /$ day, with over $45 \%$ of the population residing in it.

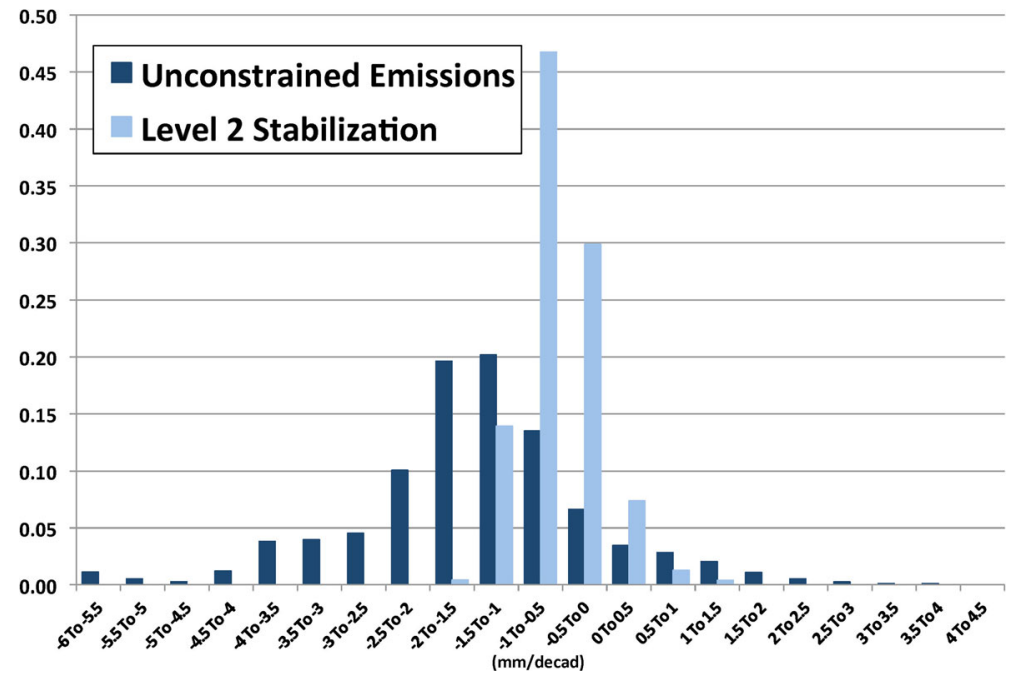

Fig. 7 Hybrid frequency distributions (HFDs) of decadal averaged September-November (SON) mean precipitation change (with respect to the last decade of the 20th century). The changes are area averaged for the Eastern Zambezi (EZMB) region. Shown are the decadal-averaged changes at 2050, based on the no-policy IGSM ensemble simulation (dark blue bars) and the Level 2 stabilization scenario (light blue bars) 


\section{Closing remarks}

We have presented results from a numerical hybridization technique that provides a probabilistic survey of the potential climatic shifts in precipitation and near-surface air temperature over the greater Zambezi River Basin. The results are presented as "hybrid frequency distributions" that are based on a core ensemble of simulations with the MIT IGSM of an unconstrained emissions pathway and a modest climate-policy scenario aimed to limit greenhouse gas concentrations by the end of this century. These simulations are combined with "climate-change pattern kernels" based on results from the CMIP3 climate model collective, and results in a meta-ensemble of potential climate outcomes. These hydro-climatic outcomes are used as inputs into regional impact models of agricultural productivity, infrastructure damage, as well as a computable general equilibrium model of the Mozambique economy. A synopsis of the climate-change pattern kernels and the hybrid frequency distributions (HFDs) is provided in support of the impacts assessment work presented in the complementary papers of this special issue.

The climate-change pattern kernels show a robust spatial consistency across all seasons, and indicate that over the ZRB the warming is enhanced with respect to the zonal trend provided by the IGSM. This is consistent with previous analyses with climate models indicating a "colder ocean, warmer land" feature prevalent in most climate-change projections. For precipitation, a majority of the region, on average, should experience an enhanced drying with respect to the zonal trend. However, this generalization is somewhat misleading in that the individual climate-change kernels exhibit a rich variety in the locations of drier and wetter conditions. Further, there is a notable seasonality in the patterns, which indicates the strongest relative drying to occur in the spring over most of the region. Nevertheless, the resulting changes in precipitation and surface-air temperature are a result of the fusion of the patternchange kernels and the zonal IGSM trends.

The resulting projections from the regional constructions are presented by averaging the precipitation and $T_{a}$ changes over the EZMB and WZMB regions. In addition, results for the spring and summer seasons presented given their importance to agricultural productivity and that these seasons, climatologically speaking, contain the highest precipitation rates. Overall, the most significant response to climate policy is seen in the distributions of spring precipitation change. In both basins, the unconstrained emission HFDs indicate a majority of the outcomes to result in a drying by 2050 , although the distribution also covers a wide range of changes and span increased and decreased precipitation. Through the climate policy considered, the HFDs' total range of outcomes collapse considerably, and perhaps more importantly, the modal portion of the distribution becomes aligned with zero precipitation change. For summer precipitation, the most salient effect of the climate mitigation scenario is to reduce the occurrence of the largest precipitation changes (both increases and decreases), thereby condensing the total width of the distribution outcomes. These shifts result in an increase in the portion of the population that resides in the modal value, however the modal value does not change considerably. For surface-air temperature, the L2S climate mitigation scenario is seen to reduce the mode value of warming at 2050, and this reduction is stronger for the distributions of the WZMB region. These shifts in the mode warming are primarily caused by the reduction in the occurrence of the most extreme temperature increases, and as a result, the minimum warming that is encompassed by these distributions is less affected.

Overall, the quantified implications and risks of these constructed climate-change distributions for the ZRB are enabled through its application in the linked framework of models. The complementary papers that are presented in this special issue will detail these results on the climate impacts. For example, given the large size of these meta-ensembles $(6,800$ members 
per scenario), a companion paper will present and discuss a Gaussian quadrature technique (Arndt et al. 2006) that reduces the total ensemble size while preserving the more important aspects of the climate-change distributions. These are applied to the hydrologic simulations of the region, and are then applied to the simulations assessing crop productivity impacts as well as damages to transportation infrastructure. The results from these impact models are then fed into a regional economic model of Mozambique to assess overall risk to its economic productivity in the coming decades.

Acknowledgments The presented analyses for the Zambezi basin were funded by United Nations University - World Institute for Development Economic Research (UNU-WIDER). The authors gratefully acknowledge this as well as additional financial support provided by the MIT Joint Program on the Science and Policy of Global Change through a consortium of industrial sponsors and Federal grants. Development of the IGSM applied in this research was supported by the U.S. Department of Energy, Office of Science (DE-FG02-94ER61937); the U.S. Environmental Protection Agency, EPRI, and other U.S. government agencies and a consortium of 40 industrial and foundation sponsors. For a complete list see http://globalchange.mit.edu/sponsors/current.html. The authors also thank two anonymous reviewers whose comments led to an improved paper.

Open Access This article is distributed under the terms of the Creative Commons Attribution License which permits any use, distribution, and reproduction in any medium, provided the original author(s) and the source are credited.

\section{References}

Arndt C, Kozlitina J, Preckel PV (2006) Efficient survey sampling of households via Gaussian quadrature. J Royal Stat Soc: Series C (Applied Statistics) 55:355-364. doi:10.1111/j.1467-9876.2006.00537

Broccoli AJ, Lau NC, Nath MJ (1998) The cold ocean-warm land pattern: model simulation and relevance to climate change detection. J Clim 11:2743-2763

Hachigonta S, Reason CJC, Tadross M (2008) An analysis of onset data and rainy season duration over Zambia. Theor Appl Climatol 91:229-243

Meehl GA, Covey C, Delworth T, Latif M, McAvaney B, Mitchell JFB, Stouffer RJ, Taylor KE (2007) The WCRP CMIP3 multi-model dataset: a new era in climate change research. Bull Am Meteorol Soc 88:1383-1394

Novella, Nicholas S., Wassila M. Thiaw, 2013: African Rainfall Climatology Version 2 for Famine Early Warning Systems. J. Appl. Meteor. Climatol., 52, 588-606. doi: http://dx.doi.org/10.1175/JAMC-D-11-0238.1

Schlosser, CA, and K Strzepek, 2013: Regional climate change of the greater Zambezi river basin: A hybrid assessment, UNU-WIDER Discussion Paper, available at: http://www.wider.unu.edu/publications/workingpapers/2013/en_GB/wp2013-040/.

Schlosser CA, Gao X, Strzepek K, Sokolov A, Forest C, Awadalla S, Farmer W (2012) Quantifying the likelihood of regional climate change: a hybridized approach. J Clim. doi:10.1175/JCLI-D-11-00730.1

Sokolov AP, Stone PH, Forest CE, Prinn R, Sarofim MC, Webster M, Paltsev S, Schlosser CA, Kicklighter D, Dutkiewicz S, Reilly J, Wang C, Felzer B, Jacoby HD (2009) Probabilistic forecast for 21st century climate based on uncertainties in emissions (without policy) and climate parameters. J Clim 22:5175-5204. doi:10. 1175/2009JCLI2863.1

Thiemig, V, R Rojas, M Zambrano-Bigiarini, V Levizzani, AD Roo, 2012: Validation of Satellite-Based Precipitation Products over Sparsely Gauged African River Basins. J. Hydrometeor, 13, 1760-1783. doi: http://dx.doi.org/10.1175/JHM-D-12-032.1

Webster M, Sokolov AP, Reilly JM, Forest CE, Paltsev S, Schlosser CA, Wang C, Kicklighter DW, Sarofim M, Melillo J, Prinn RJ, Jacoby HD (2011) Analysis of climate policy targets under uncertainty. Clim Chang 61: 295-320 